\title{
Festschrift for Professor Lesley Rees MD FRCPCH
}

\author{
Michel Baum ${ }^{1}$
}

Published online: 19 June 2021

(C) IPNA 2021

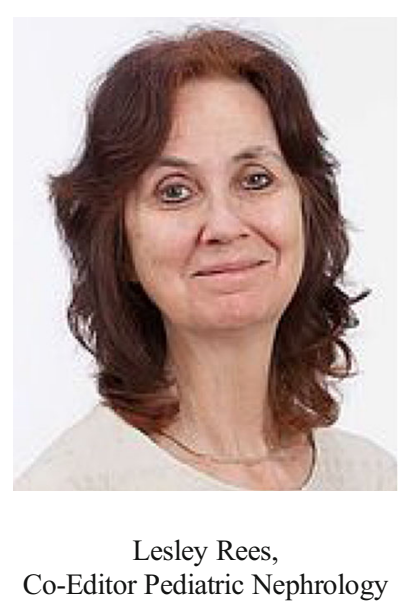

I have the honor of editing this festschrift for Professor Lesley Rees who is a great friend and colleague to us all. Lesley has been a Pediatric Nephrologist for over 35 years. For the last 30 years, she has worked at Great Ormond Street Hospital, and is also a Professor at University College London. During her career, she has made major contributions to the most important problems facing children with chronic kidney disease including growth and nutrition, bone and mineral disease, and the cardiovascular disease that afflicts our patients. Her work has improved our understanding of the impact and pathogenesis of vascular calcification. Despite her numerous clinical and administrative responsibilities, she has published well over 100 manuscripts and reviews. She has received over $\$ 2.5$ million dollars in funding for her research. She is the senior editor of the Handbook entitled Paediatric Nephrology. As Head of the Nephrology Department at Great Ormond Street, she assembled the most talented and productive group of pediatric nephrologists in the world. She has trained countless pediatric nephrologists who have gone on to care for patients and educate the next generation of our specialty.

Her accomplishments have not gone unnoticed. She has served on Council of the International Pediatric Nephrology Association and was awarded the IPNA Lifetime Achievement award in 2016, the society's highest honor. She is loved and respected by her patients, their families, trainees, and her colleagues. Some of her closest colleagues have contributed manuscripts to this journal in her honor.

I have had the unique privilege of working closely with Lesley for the past 10 years as her co-editor of Pediatric Nephrology. Lesley was always fair, scholarly, and thoughtful in every task required of an editor. She has always been dedicated to the Journal and to IPNA. One of the greatest joys of my career has been working daily with such a wonderful colleague and friend.

Publisher's note Springer Nature remains neutral with regard to jurisdictional claims in published maps and institutional affiliations.
Michel Baum

michel.baum@utsouthwestern.edu

1 UTSouthwestern Medical Center, Dallas, TX, USA 